Inc., Ahmad Halwani Grant/research support from: Bristol-Myers Squibb, Kyowa Hakko Kirin, Roche, Abbvie, Genentech, Immune Design, miRagen, Amgen, Seattle Genetics, Takeda, Pharmacyclics

DOI: 10.1136/annrheumdis-2019-eular.3150

\section{THU0630 THE ACR'S RHEUMATOLOGY INFORMATICS SYSTEM FOR EFFECTIVENESS (RISE) DEMONSTRATES IMPROVEMENTS IN MANY MEASURES OF QUALITY OF CARE BETWEEN 2016 AND 2017}

Zara Izadi ${ }^{1}$, Gabriela Schmajuk ${ }^{1}$, Julia Kay ${ }^{1}$, Rachel Myslinski ${ }^{2}$, Jinoos Yazdany ${ }^{1}$. ${ }^{1}$ University of California, San Francisco, San Francisco, United States of America; ${ }^{2}$ American College of Rheumatology, Atlanta, United States of America

Background: The ACR's Rheumatology Informatics System for Effectiveness (RISE) is a national, EHR-enabled registry that passively collects data on all patients seen by participating practices, thus reducing the selection bias present in single-insurer claims databases. Launched in 2014, RISE is designed to help practices improve their quality of care. Objectives: The objectives of our study were to a) examine changes in practice-level performance on selected quality measures for patients with rheumatoid arthritis (RA) in 2016 and 2017 and b) assess variations in performance over time between practices.

Methods: We analyzed data collected on all patients with a diagnosis of RA who had at least one clinic visit between January 1, 2016 and December 31,2017 . Six quality measures in the areas of RA management (disease activity measurement and tuberculosis (TB) screening), and cardiovascular risk reduction (body mass index (BMI) screening in 18-64 years, BMI screening in $>64$ years, tobacco use screening and cessation, and blood pressure (BP) control) were examined. Performance on quality measures, defined as the percentage of eligible patients receiving recommended care, was examined at the practice level. We used a hierarchical linear model to predict change in practice-level measure performance per quarter, accounting for clustering by practice. We also assessed variations in within-practice performance changes over time by calculating the range for each measure.

Results: Data from 150,099 patients from 135 practices was examined Mean age was $63 \pm 14$ years, $77 \%$ were female, $72 \%$ were Caucasian The most common practice structure was a single-specialty group practice $(65 \%)$, followed by solo $(20 \%)$ and multi-specialty group practice $(10 \%)$ From January 2016 to December 2017 there was an improvement in quarterly performance on disease activity measurement $(+2.9 \%, p<0.001)$, TB screening $(+1.9 \%, \quad p<0.001)$, BMl screening in $18-64$ years $(+2.4 \%$, $p<0.001)$, and tobacco use screening and cessation $(+1.2 \%, p<0.001)$, and a decline in quarterly performance on BMl screening in $>64$ years ($0.4 \%, p<0.001)$ and $\mathrm{BP}$ control $(-0.6 \%, \mathrm{p}<0.001)$. Improvements in performance on RA management measures were steady from Q1 2016 to Q4 2017 (Figure). Within-practice change in performance varied significantly across practices (Table). For example, from 2016 to 2017 withinpractice change in performance on blood pressure control varied from a decrease by $66.7 \%$ to an increase by $100 \%$.

Conclusion: Among practices participating in RISE, from 2016 to 2017 average performance on most measures for individuals with RA improved. We found significant variations in performance over time between practices, suggesting that future work to identify workflow patterns leading to high performance or to dramatic improvements in quality are warranted. Disclaimer: This data was supported by the ACR's RISE Registry. However, the views expressed represent those of the authors, not necessarily those of the ACR.

Figure. Performance on Rheumatoid Arthritis Management Quality Measures in the RISE Registry, by quarter.

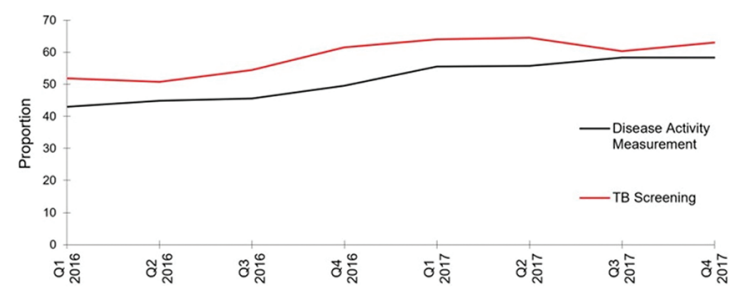

Table. Performance on Quality Measures in the RISE Registry in 2016 and 2017.

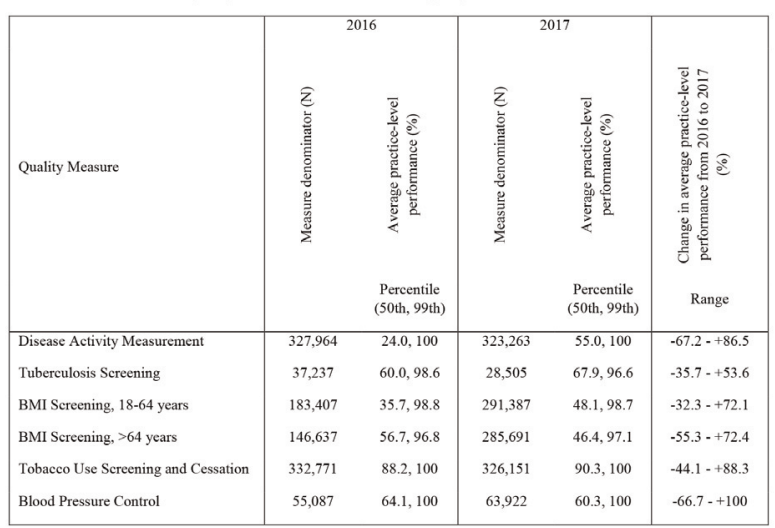

Table. Performance on Quality Measures in the RISE Registry in 2016 and 2017.

Quality Measure 20162017 Measure denominator (N) Average practicelevel performance (\%) Measure denominator (N) Average practice-level performance (\%) Change in average practice-level performance from 2016 to 2017 (\%) Percentile (50th, 99th) Percentile (50th, 99th) Range

Disclosure of Interests: Zara Izadi Consultant for: I worked as a paid consultant for Celgene from 2014 to 2017., Gabriela Schmajuk Grant/ research support from: Investigator initiated award from Pfizer from 2015 2018, unrelated to this work, Julia Kay: None declared, Rachel Myslinski: None declared, Jinoos Yazdany Grant/research support from: Pfizer, Consultant for: AstraZeneca

DOI: 10.1136/annrheumdis-2019-eular.5154

\section{THU0631 IMPACT OF DAY OF ADMISSION AND TIME TO DIAGNOSTIC ARTHROCENTESIS ON MORTALITY AND OTHER OUTCOMES IN SEPTIC ARTHRITIS: A NATIONWIDE ANALYSIS}

Gustavo Contreras, Ana B Arevalo, Shane Murray, Yiming Luo, Faris Haddadin. Icahn School of Medicine at Mount Sinai St Luke's - West Hospitals, Internal Medicine, New York, United States of America

Background: Multiple studies have been done assessing the "weekend effect" and outcomes for hospitalized patients ${ }^{1,2,3,4}$, however, there is no data evaluating the outcome of patients with septic arthritis of a native joint (SANJ) who are admitted on the weekend compared to the rest of the week.

Objectives: To evaluate whether important outcomes in SANJ, including in-hospital mortality, differ between patients admitted on weekends versus weekdays and the time to diagnostic arthrocentesis.

Methods: The National Inpatient Sample (NIS) database of the year 2016 was utilized for patients admitted to the hospital with a principal discharge diagnosis of SANJ. This was a retrospective cohort study of patients hospitalized in 2016 with SANJ in hospitals across the US Patients were included if they were adults with a principal diagnosis of SANJ based on ICD-10 codes. Admissions between midnight Friday and midnight Sunday were classified as weekend admissions. Early arthrocentesis was defined as percutaneous arthrocentesis performed within 24 hours of admission. The proportion of patients with SANJ admitted over weekends versus weekdays was determined. Odds ratios (OR) were calculated for primary and secondary outcomes including in-hospital mortality rate, rates of diagnostic arthrocentesis and early arthrocentesis, length of stay and total hospital charges, These results were compared after multivariable logistic regression adjusted for age, gender, race, day of admission, Charlson comorbidity index and median household yearly income in the patient's zip code. We used STATA-15 for statistical analysis.

Results: The study included 12819 patients with SANJ. Compared with patients admitted on weekdays, patients with SANJ admitted on weekends had increased in-hospital mortality rates (adjusted odds ratio[aOR] 3.67; 95\% [Cl] $1.52-8.86, \mathrm{p}<.005)$, but similar early arthrocentesis rates ([aOR] 1.14; 95\%, [Cl] $0.90-1.45 p>0.05)$, length of stay $(p>0.05)$ and hospital charges (\$2751.11; 95\% [Cl] -4449.6 - 9951.8; P>0.05). However, regardless of the day of admission those who received an early arthrocentesis had lower length of stay $(-1.46, p<0.05)$, and lower total hospital charges (\$ -6527 \$; p<0.05). 
Conclusion: This study showed that compared with patients admitted on weekdays, patients with SANJ admitted on weekends had increased mortality rates but similar length of stays and total hospital charges. However, patients who received an early arthrocentesis had significantly lower length of stay and hospital charges regardless of the day of admission. This results add weight to the hypothesis of negative outcomes in weekend admissions. Moreover, we believe that our findings require further investigation to establish the role of early arthrocentesis in the management of septic arthritis.

\section{REFERENCES:}

[1] Bell CM, Redelmeier DA. Mortality among patients admitted to hospitals on weekends as compared with weekdays. N Engl J Med 2001;345:663-8.

[2] Pauls LA, et al. The Weekend Effect in Hospitalized Patients: A Meta-Analysis. J Hosp Med. 2017 Sep;12(9):760-766.

[3] Honeyford K, et al. The weekend effect: does hospital mortality differ by day of the week? A systematic review and meta-analysis. BMC Health Serv Res. 2018 Nov 20;18(1):870

[4] Kostis WJ, Moreyra AE. Severity of illness and the weekend effect. Lancet. 2017 Oct 14;390(10104):1734-1735.

Disclosure of Interests: None declared

DOI: 10.1136/annrheumdis-2019-eular.5197

\section{THU0632 A POPULATION-BASED STUDY OF TUBERCULOSIS INCIDENCE AMONG RHEUMATIC DISEASE PATIENTS UNDER ANTI-TNF TREATMENT}

Natália Sartori ${ }^{1}$, Rafael Chakr ${ }^{2}$, Afonso Papke ${ }^{2}$, Paulo Picon ${ }^{3}$, Jeruza Neyeloff ${ }^{4}$. ${ }^{1}$ Hospital de Clínicas de Porto Alegre, Department of Rheumatology, Porto Alegre, Brazil; ${ }^{2}$ Hospital de Clínicas de Porto Alegre, Department of Rheumatology, Porto Alegre, Brazil; ${ }^{3}$ Hospital de Clínicas de Porto Alegre, Department of Internal Medicine, Porto Alegre, Brazil; ${ }^{4}$ Hospital de Clínicas de Porto Alegre, Porto Alegre, Brazil

Background: Tuberculosis (TB) is an infectious disease caused by Mycobacterium tuberculosis, with a high incidence in the general population of Brazil. The advent of immunobiologic therapy with anti-TNF agents for rheumatic diseases, despite achieving substantial efficacy in controlling disease activity, has been associated with a significant increase in incident cases of tuberculosis in this population due to blockade of TNF, which is responsible for maintenance of granuloma structure.

Objectives: Estimate the incidence of tuberculosis in Public Health System patients receiving anti-TNF therapy for rheumatic diseases. As secondary objectives, we sought to evaluate mortality and the influence of screening for latent tuberculosis infection on clinical outcomes in this population.

Methods: This retrospective cohort study included all Public Health System patients from the Brazilian state of Rio Grande do Sul (RS) who received prescriptions of anti-TNF agents for treatment of rheumatic diseases between 2006 and 2016. All data were obtained from official government records (drug dispensing, tuberculosis reporting, and mortality) where notification was mandatory. For a subset of patients, latent tuberculosis screening data were obtained through a review of medical records.

Results: A total of 5853 patients were included from 2006 to 2016, out of which $3653(62.4 \%)$ had rheumatoid arthritis, $1150(19.7 \%)$ had ankylosing spondylitis, 872 (14.9\%) had psoriatic arthritis, and $123(2.1 \%)$ had juvenile idiopathic arthritis. Overall, 43 cases of TB were found, with an incidence of 734.7 cases per 100,000 exposed, which corresponds to 2.86 per 1000 person-years exposed. Two hundred and fifty deaths occurred in this cohort. In a subgroup of patients recruited from the outpatient rheumatology clinic of Hospital de Clínicas de Porto Alegre $(n=$ 268 ), screening for latent tuberculosis infection (LTBI) was performed in $86 \%$ of patients before initiation of anti-TNF therapy; $30.1 \%$ had a positive tuberculin skin test. LTBI treatment was administered to 74 patients. In this subgroup of patients, 5 cases of TB were diagnosed, 2 in patients who had previously completed LTBI treatment.

Conclusion: In this population-based study, a high incidence of tuberculosis among patients with rheumatic diseases exposed to anti-TNF agents was found, reinforcing the need for screening and treatment of LTBI to reduce the risk of reactivation of granulomatous disease. No significant impact on mortality was demonstrated.

\section{REFERENCES:}

[1] Gómez-Reino JJ, Carmona L, Rodríguez Valverde V, Mola EM, Montero MD. Treatment of rheumatoid arthritis with tumor necrosis factor inhibitors may predispose to significant increase in tuberculosis risk: A multicenter active-surveillance report. Arthritis Rheum. 2003;

[2] Arkema E V, Jonsson J, Baecklund E, Bruchfeld J, Feltelius N, Askling J. Are patients with rheumatoid arthritis still at an increased risk of tuberculosis and what is the role of biological treatments? Ann Rheum Dis. 2014;

[3] Gomez-Reino JJ, Carmona L, Angel Descalzo M. Risk of tuberculosis in patients treated with tumor necrosis factor antagonists due to incomplete prevention of reactivation of latent infection. Arthritis Rheum. 2007;

[4] Yonekura CL, Oliveira RDR, Titton DC, et al. Incidência de tuberculose em pacientes com artrite reumatoide em uso de bloqueadores do TNF no Brasil: dados do Registro Brasileiro de Monitoração de Terapias Biológicas BiobadaBrasil. Rev Bras Reumatol. 2017.

Disclosure of Interests: None declared

DOI: 10.1136/annrheumdis-2019-eular.3740

\section{THU0633 ECONOMIC IMPACT OF HEALTHCARE RESOURCE UTILIZATION AND WORK DISABILITY IN PORTUGUESE PATIENTS WITH ANKYLOSING SPONDYLITIS: RESULTS FROM THE ASSESSMENT OF RESULTS IN ANKYLOSING SPONDYLITIS(AREA) STUDY}

Filipe Araújo ${ }^{1}$, Cláudia Duarte ${ }^{2}$, Jorge Brandão ${ }^{3}$, Rui Cernadas ${ }^{4}$, Elsa Mateus ${ }^{5}$, Luís Cunha Miranda ${ }^{6}$, José Canas Da Silva ${ }^{7}$, José Gomes Da Silva ${ }^{8}$, Pedro Simões Coelho ${ }^{2}{ }^{1}$ Hospital de Sant'Ana, Rheumatology and Osteoporosis Unit, Parede, Portugal; ${ }^{2}$ NOVA IMS Information Management School, Lisboa, Portugal; ${ }^{3}$ Apmgf - Associação Portuguesa De Medicina Geral E Familiar, Lisboa, Portugal; ${ }^{4}$ Serviços Médicos Continental, Gaia, Portugal; ${ }^{5}$ Liga Portuguesa Contra as Doenças Reumáticas, Lisboa, Portugal; ${ }^{6} I P R$ - Portuguese Institute of Rheumatology, Lisboa, Portugal; ${ }^{7}$ Hospital Garcia de Orta, Almada, Portugal; ${ }^{8}$ National Association of Ankylosing Spondylitis, São Domingos de Rana, Portugal

Background: Ankylosing spondylitis (AS) has a significant burden upon the individual, family and society. Understanding the economic impact of AS is crucial to substantiate policies that promote early referral, diagnosis and treatment.

Objectives: To assess the economic impact of AS in Portugal concerning healthcare utilization and work disability.

Methods: The Assessment of REsults in Ankylosing spondylitis (arEA) study was developed by the NOVA-Information Management School (Lisbon) in collaboration with the Portuguese Society of Rheumatology, the Portuguese Association of Family Physicians, the National Association of Primary Care Units, the National Association of AS Patients and the Portuguese League Against Rheumatic Diseases. The arEA aimed at assessing reasons for delayed diagnosis of $A S$, as well as disease impact in patients' lives, global health and work. A comprehensive online survey was developed and sent to AS patients. Data on demographics, lifestyle habits, daily life activities, working habits, disease indexes and healthcare utilization was retrieved. Costs of the disease for patients resulting from the use of health systems was obtained thorough patient's declaration, the cost for the national health service (SNS) was obtained combining primary data and secondary data related with the average costs of service use. Finally, the impact over the economy was also estimated through the participation of patients in labor market and using as mediator variables the absenteeism and presenteeism. A set of generalized lin ear models were used to identify the factors with significant effect over health status, SNS costs and impact over economy.

Results: 354 patients responded the survey, $42.1 \%$ female, more frequently from the 35-44 year-old age group. In the previous 12 months, $76 \%$ reported using the National Healthcare System (SNS) for AS-related reasons (85\% outpatient visits; $74 \%$ diagnostic exams; $48 \%$ ER visits; $8 \%$ inpatient admissions). During that period, estimated SNS expenditure with AS patients reached $€ 47$ million, excluding costs with medication (ongoing analysis), distributed as: outpatient visits $€ 25$ million, diagnostic exams $€ 7$ million, ER visits $€ 3$ million and inpatient admissions $€ 12$ million. Adding to this, patients spent on average $€ 84$ million out of their own pocket on AS-related expenses $(€ 1.786$ per patient: outpatient visits $€ 245$, diagnostic exams $€ 151$, ER visits $€ 48$, inpatient admissions $€ 415$, medication $€ 593$, travelling expenses $€ 334)$. Regarding work disability, working AS patients reported an average of 12 days on leave of absence and 25 days on sick leave per year, with an estimated cost of $€ 28$ and $€ 57$ million, respectively. Presenteeism led to a loss of 73 working days with a cost of $€ 165$ million. Taking also into account patients with prolonged leaves of absence ( $€ 72$ million), permanent leaves ( $€ 18$ million), unemployed ( $€ 50$ million) and family medical leaves (€ 47 million), the overall costs with work disability in AS reached $€ 437$ million in one year. 